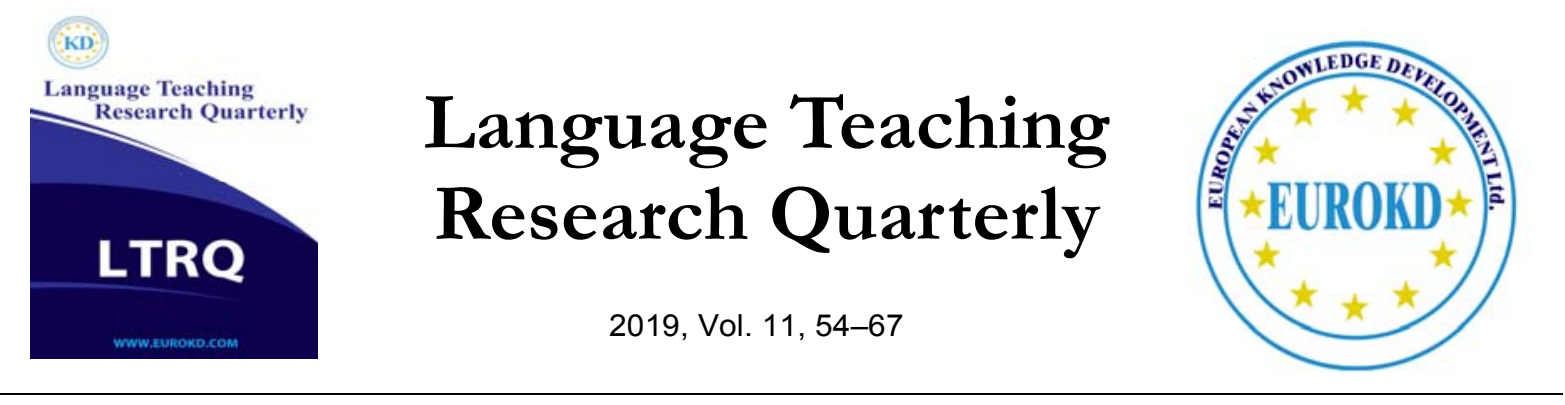

\title{
"MulDiLanguaging" for Fostering Intercultural Communicative Competence in Second/Foreign Language Education
}

\author{
Eleni Griva ${ }^{1}$, Isaak Papadopoulos ${ }^{2 *}$ \\ ${ }^{1}$ Professor of Applied Linguistics University of Western Macedonia, Greece \\ ${ }^{2} \mathrm{Ad}$. Teaching Staff Member of Linguistics European University Cyprus, Cyprus
}

\begin{abstract}
Received 07 July 2019
Accepted 10 September 2019

Abstract

In this paper, an attempt is made to develop a framework of a "MulDiLanguaging" approach with the purpose to enhance primary school students' intercultural competence. This educational framework consists of three interactive - interdependent components: a) Intercultural/multicultural sensitivity and awareness, b) Intercultural cooperation and communication, c) Language and intercultural communication strategies. It includes communicative and creative activities aiming at developing students' intercultural communicative skills in parallel with their target language skills (EFL). In the "MulDiLanguaging" framework, the students are trained to acquire knowledge of 'self' and 'other', knowledge of everyday life in different cultural contexts, to function fully in an intercultural situation, as well as to develop language skills and abilities in the target language and intercultural communication strategies. A number of communicative and creative activities are presented with the purpose to create a group-working, cooperative context and enhance students' intercultural competence. Also, an Intercultural Portfolio is suggested as an alternative tool for assessing students' linguistic skills and strategies and their intercultural communication skills acquired in the "MulDiLanguaging" setting.
\end{abstract}

Keywords: MulDiLanguaging, Second/Foreign Language, Intercultural Awareness, Communication, Greek Education

\section{Introduction}

The landscape of education in Greece has changed over the last years, because of the mobility and immigration in Europe, with the advent of a significant number of bilingual students in mainstream classrooms (Griva \& Stamou, 2014). As a result, the Greek classrooms have become multicultural 'places', where students have to be respectful of diverse customs and cultural 
practices and acknowledge differences in nonverbal communication styles, so that they can achieve successful intercultural communication and effective learning outcomes (Griva \& Kofou, 2019; Griva \& Papadopoulos, 2019). This multicultural educational environment composed of indigenous students (Greek speaking) and immigrant/refugee students (being included) has intensified the need for developing immigrant/refugee students' skills but indigenous Greek speaking students' skills, as well.

In this paper an attempt was made to develop: a) intercultural sensitivity and awareness of students, by leading them to acquire knowledge of 'self' and 'other', knowledge of everyday life in different cultural context, to function fully in an intercultural situation; b) intercultural cooperation and communication which presupposes the students' tendencies to accept difference and their willingness to engage with the target culture, self-awareness (Rose, 2004, cited in Yassine 2006) and c) language skills and abilities in the target language (EFL) and intercultural communication strategies. Hence, special emphasis will be placed on providing a descriptive account of these three principles Muldilanguaging approach has been developed around, so that a clearer understanding of its application can be achieved. Based on the above, intercultural assessment is promoted as a necessity in the teachers' attempt to delve into and assess the students' intercultural competence within culturally and linguistically diverse classrooms.

\section{Defining and Identifying Intercultural Awareness and Communication Intercultural Sensitivity and Awareness}

Cultural sensitivity has been placed in the center of the research attention especially among scholars who are engaged in studies related to intercultural education (Anderson et al., 2006; Bennett, 2004; Hammer et al., 2003). It is defined as "the ability to be sensitive to cues that are often subtle or unfamiliar and to adjust behavior and expectations accordingly" (Stone, 2006, p. 348). Focusing on intercultural sensitivity, it is worth mentioning that it is used within the context of interaction and communication between members of diverse groups and it involves these skills or competences that are required for a smooth cross-cultural contact (Bennett, 2010; Griva \& Zorbas, 2017). Intercultural sensitivity is considered to be a major variable in allowing people to live and work with people with different cultural backgrounds (Landis \& Bhagat, 1996), as it is stressed on the importance of cultural differences and on the viewpoints of people from different cultural background (Bhawuk \& Brislin, 1992).

What is worth underlining is Bennett's (1993) claims that intercultural sensitivity does not constitute an inherent human trait but it develops through experience from the people's acting within a culturally-diverse environment, developing a sense of understanding cultural differences in a more complex way (Hammer et al., 2003). Indeed, Bennet's model (1993) describes intercultural sensitivity moving from early ethnocentric stages which include 'Denial', 'Defence' and 'Minimisation' phases, to advanced ethnorelative stages involving 'Acceptance', 'Adaptation' and 'Integration' phases. Special emphasis is placed on the multidimensional character of intercultural sensitivity and its development which moves through cognitive, affective, and behavioural dimensions. That is why, fostering intercultural sensitivity implies the 
competencies of empathy and multiple perspective-taking (Lambert \& Barley, 2001) and encorporates all these skills needed for acting efficiently in a multicultural and multidimensional environment.

In parallel, intercultural awareness constitutes another important factor of acting efficiently within a culturally diverse context. Intercultural awareness is regarded as the minimum condition for interculturally competent individuals in the global village while research has shown that it is this "tool" that can develop one's communication skills while lessening the likelihood of misunderstandings in intercultural interactions (Seidel, 1981). According to Chen and Starosta (2000), intercultural awareness is the cognitive aspect of intercultural communication competence, which refers to the understanding of cultural conventions that influence the way people think and behave. It is in fact this field that emphasized the changing of personal thinking about the environment through understanding distinct characteristics of one other cultures (Triandis, 1977). Therefore, people should understand the cultural variability so that they can modify the communication patterns to be congruent with the cures of unfamiliar interactants. Intercultural awareness is a dynamic process which goes through three levels with special importance. The first level is related to a person's understanding of another culture through being based mainly on stereotypes, thus the awareness of this level is considered to be superficial, emerging most usually from media and tourist leaflets.

Moving on with deeper levels of awareness, people can acquire an awareness of significant and subtle traits of a culture through direct or indirect (second hand) experience. While at this level, either conflict situations or intellectual analysis can occur. As regard to the first - culture conflict- people tend to have the feeling of cultural shock in the process of intercultural adjustment. When it comes to the latter - intellectual analysis- according to Thomas and Althen (1989), people start to appreciate and respect the new culture and develop sensitivity towards the difference.

Concerning the third level of intercultural awareness, people tend to develop the ability of empathy which can assist people to see the other culture from an insider's perspective. It is the advantageous impact of flexibility that facilitates our understanding of what the insider's mind has and further our estimation of behaviours or internal states of counterparts that are different from one culture to another (Campbell et al., 2005, p.197). Hence, this developmental process of intercultural awareness is viewed as a part of cognitive function which is closely related to the knowledge of 'self' and 'other', the knowledge of everyday life in different cultural context which can help people to function fully in an intercultural situation.

\section{Intercultural Cooperation and Communication}

Intercultural sensitivity and awareness are regarded as two basic components of intercultural competence, which is defined as the set of values, attitudes, skills, knowledge, and understanding that are needed for understanding and respecting people from culturally different, for interacting and communicating effectively and appropriately with such people (Barrett, 2013, 2018). 
According to Chen and Starosta (1996), intercultural communication competencies comprised of three dimensions: intercultural awareness, intercultural sensitivity, and intercultural adroitness.

Intercultural competence requires valuing cultural diversity, openness to cultural otherness, respect for other people and for other beliefs and tolerance of ambiguity. It also requires the skill and ability to translate this cultural knowledge into communication behaviors, skills of listening and observing, flexibility and adaptability, linguistic, communicative, and plurilingual skills. Understanding and accepting people who belong to different cultural backgrounds, identities and beliefs would lessen misunderstandings, taboos and conflicts (Songul \& Akbarov, 2016).

Promoting the development of cooperation and communication within culturally-diverse classrooms means promoting students' ability to develop, maintain and appropriately modify interdependent relationships with others to succeed in achieving goals (Kreijns, 2004). It is clear that there are numerous actions that can be taken by teachers to promote the intercultural competence of young student. Teaching should focus on training students to interact appropriately and effectively in multicultural contexts, to develop intercultural competence and intercultural communication skills, including: i) communication as a tool for the construction of the social/cultural identity through the negotiation of the message, ii) communication as a 'transmitter/transfer' of social/cultural relations (Chen, 2014; Griva \& Papadopoulos, 2019; Ward, et al., 2011).

Within this framework, the development of positive attitudes towards other group members, is enhanced which entails to strong social relationships and group cohesion. To put it in another way, it is what Johnson and Johnson (1989) supported underlining the importance of cooperative activities that through interaction and cooperation positive interdependence is promoted which means that every member of a group is linked with the others in such a way that he/she cannot succeed unless they do (and vice versa).

Nevertheless, in culturally-diverse classrooms, there is a possibility that language difficulties restrict the effectiveness of interaction which affects directly the development of relevant interpersonal and small group skills (Baker \& Clark, 2010). Besides, every student brings in the classroom different ways and practices of reasoning and working and different perspectives which may cause various challenges that need to be taken into consideration. Conflicts among students might emerge due to differences in each student's background. Indeed, people have the tendency to form working groups with those with whom they share similar backgrounds and interests (see Teilman et al., 2012). Given the aforementioned, promoting the formation of groups consisting of people with different cultural background could facilitate the gradual development of a sense of identity and purpose, which further enhances the interaction of students and the reduction of stereotypical visions about other group members (Coelho, 1998).

According to a large-scale study of Griva and Papadopoulos (2018), a proposal for developing certain skills of intercultural cooperation and communication has been attempted as an answer to the teachers' needs. In particular, the students should show interest in working with speakers/classmates from other cultural contexts and feel the wish to be actively engaged into group activities or encourages others to collaborate in groups. Moreover, it is very important that 
students of multicultural classrooms build a relationship with a speaker/classmate from another cultural context and attempt to resolve conflicts/disputes through discussion and decision taking. Furthermore, the students should develop abilities and skills which can help them to solve problems related to the interaction/communication with a speaker/classmate from another cultural context as certain challenges may arise (e.g. different communication styles).

Within such a context, students have to develop those skills and abilities that are required to effectively address, manage andresolve conflicts within a culturally-diverse context in a peaceful and cooperative way. More specifically, they have to be able to identify, analyse, relate and contextualise the causes and otheraspects of conflicts occurred while, they have to further identify common ground on which agreement between conflictingparties can be built, identify options for resolving conflicts, and refine possible compromises or solutions. As regards to the teaching practice context, the promotion of formulating heterogeneous groups including students from different cultural background and the encouragement of these students to cooperate could lead to inter-ethnic friendships, cross-cultural understandings, and a sense of teamwork, as well as could result into enhancing literacy and language acquisition among linguistically diverse students (Crandall et al., 2001; Saravia-Shore \& Garcia, 1995; Snowman \& Biehler, 2003).

\section{The "MulDiLanguaging" Educational Setting}

In this section the authors outline a framework of a "Muldilanguaging" approach with the purpose to develop primary school students' intercultural competence. This educational framework consists of communicative and creative activities aiming at enhancing students' intercultural communicative skills in parallel with their target language skills (EFL). The "muldilanguaging" educational context consists of three interactive - interdependent components:

\section{Intercultural/multicultural sensitivity and awareness}

By being engaged into the interactive context, children are enabled to acquire knowledge of 'self' and 'other', knowledge of everyday life in different cultural contexts, to function fully in an intercultural situation (Kramsch, 1993, pp. 233-259). They are also provided with a number of opportunities to develop various competencies, such as: comparing and contrasting cultures, dealing with or tolerating ambiguity.

\section{Intercultural cooperation and communication}

Developing certain skills of intercultural cooperation and communication is attempted. The students are trained to develop abilities and skills which can help them to solve problems related to the interaction/communication with a speaker/classmate from another cultural context as certain challenges may arise. The students are provided with opportunities to exhibit their capability and readiness towards assisting other members to resolve conflicts through enhancing their understanding of the options available to them in parallel with accepting difference and defending his/her own point of view, while acknowledging the legitimacy of others. 


\section{Language and intercultural communication strategies}

The teacher is encouraged to integrate "other-cultural" elements in his/her class and raise appropriate communication strategies to students with the purpose to facilitate his/her students' readiness to use the target-language as a medium of communication and at the same time to be able to effectively act within intercultural speech events within the national or international context, demonstrating an intercultural competence.

Table 1

Implementing Activities in the "Muldilanguaging" Setting

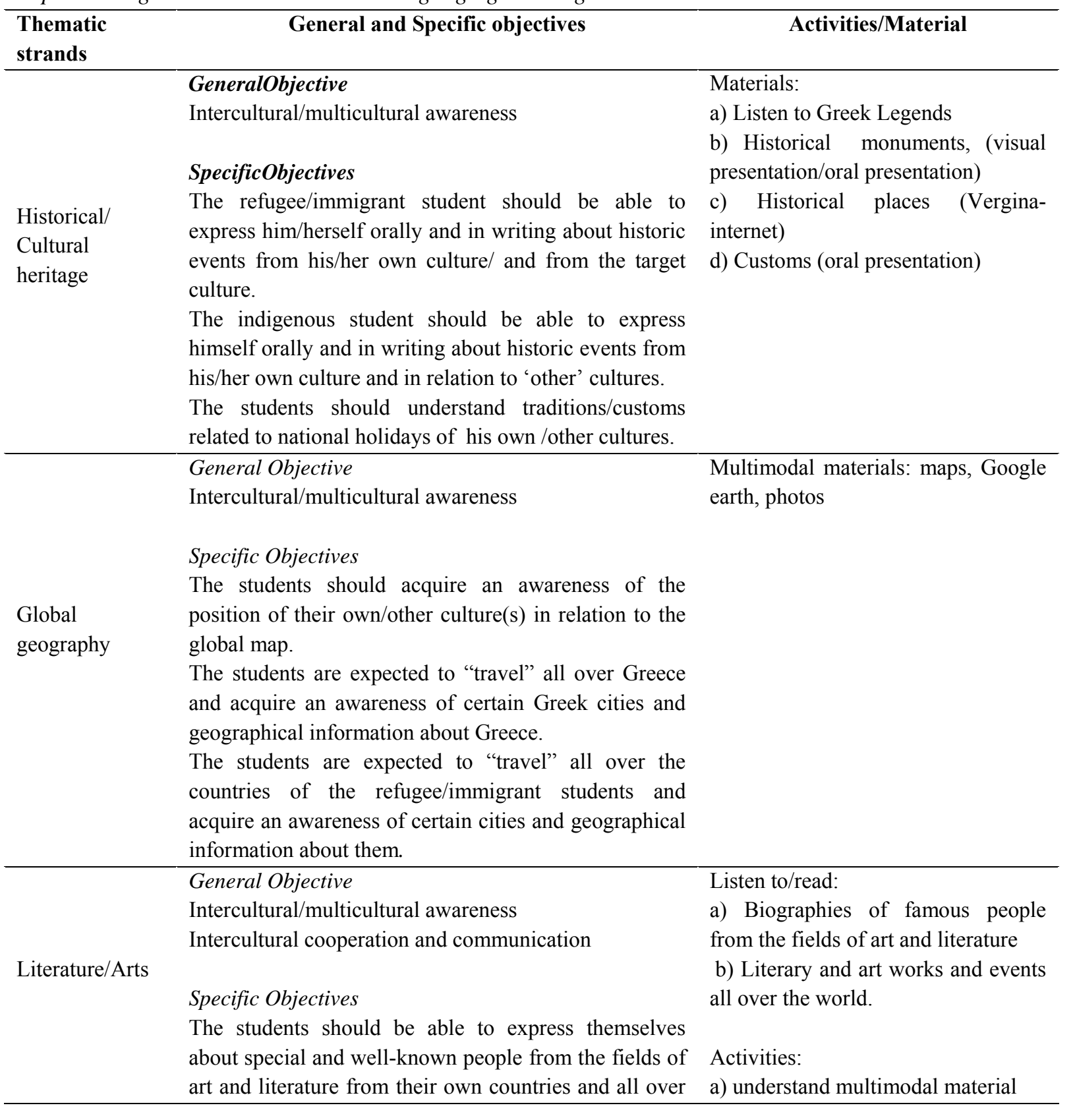




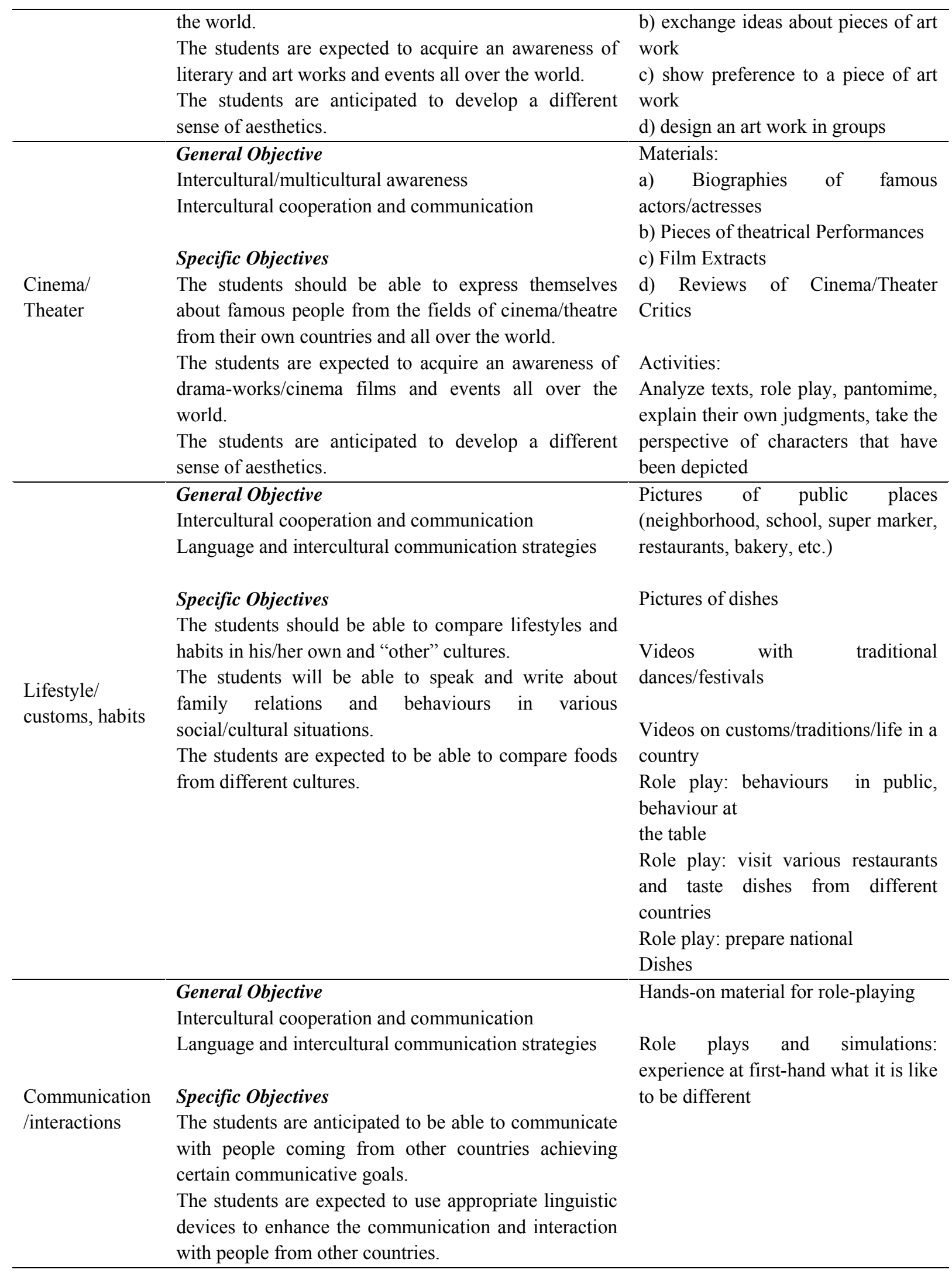


The students should be able to serve as effective

mediators within intercultural communicative events

and situations.

\section{Thematic Strand: "Historical/Cultural Heritage"}

Concerning the first thematic strand "Historical/Cultural Heritage", the students are made to raise their intercultural/multicultural awareness within a multimodal learning and teaching environment. In particular, an attempt is made towards empowering the refugee/immigrant students' abilities to express themselves orally and in writing about historic events from Greece and their own countries. Moreover, the indigenous students should be able to express themselves orally and in writing about historic events from their own culture and in relation to 'other' cultures within a context of mutual understanding of traditions/customs related to national holidays of their own /other cultures.

Towards those goals, the use of multimodal educational material is encouraged within a teaching context. More specifically, the students may deal with legends from their countries which can constitute a source and stimulus for discussion in the target language. In parallel and given the fact that legends are loaded with cultural features of each country, the language of the students' origin can also be welcomed. As for the Greek context, the teachers may make use of the "Myth of the legendary Odysseus", "Myth of Jason and the Argonauts" or the well-known legend about "The name giving of Athens". Both the indigenous and the immigrant/refugee students can also read certain legends being brought to school by immigrant/refugee students and discuss their topics, the heroes and the messages derived from them, highlighting also historical and cultural aspects of their countries.

Moreover, historical monuments and places can also become contents of focus within this context. In fact, both visual and oral representations can be followed in the teachers' attempt to raise students' awareness of historical monuments such as "The Parthenon", "The White Tower of Thessaloniki", "The Ancient Theatre of Larissa" and incite discussion among indigenous and immigrant/refugee students on monuments of Greece and the 'foreign' countries. Apart from the Historical Monuments, the students may be encouraged to focus their attention on historical places of Greece and other cultures like "Vergina", "TheSchool of Aristotle" and the "Oracle of Delphi" which have long been acknowledged among the most important places in Greece. Concerning the refugee/immigrant students, they can bring photos or information from some historical places and monuments of their countries, give some information to the Greek students about the importance of these monuments, and explain some potential special features of them.

Last, the traditional customs of each country could also lead students to acquire an awareness of the cultural heritage of the target countries. In particular, and given that each city or prefecture in Greece has a different traditional custom, it is advisable students discuss about customs both from Greece and from the countries of the immigrant/refugee students. They may seek for similarities and differences, while they may be encouraged to discuss the reason each custom has been designed in a particular way, basically the lifestyle and the weather conditions being the main influential reason. In this way, both indigenous and immigrant/refugee students may have 
the opportunity to see traditional dances as well, in which the dancers wear the traditional customs.

\section{Thematic Strand: Global Geography}

Regarding the second thematic strand "Global Geography", the students are expected to raise their intercultural/multicultural awareness within an educational environment which fosters multi/interculturalism. More specifically, the students should acquire an awareness of the position of their own/other culture(s) in relation to the global map. In parallel, they are expected to "travel" all over Greece and all over the countries of the refugee/immigrant students and acquire an awareness of certain Greek and foreign cities and geographical information about Greece and the countries of the immigrant/refugee students.

Within this context, an attempt is made towards utilising multimodal materials. In particular, the students will be engaged in Map-reading activities spotting their countries in the global map while at the same time, they are also using google earth application to navigate virtually to these countries. In this way, students will be provided with certain information about the geography of the countries, they will compare their geomorphological features, their flora and fauna. Furthermore, the teachers may make use of the ready-to-use pictures that google earth offers and it would be great for the students to create a collage of these pictures.

Towards that goal, students are expected to bring personal photos from their countries/cities. It would be of utmost important for students to bring photos from personal or family moments, as in this way they will feel more confident to present in front of the classmates in the target language. Students may also share photos, express their views and their perspectives as regards to the scene depicted in the pictures. The students may also create digital puzzles through scanning the photos or create hands-on collages including the photos that the students may bring to school. This may become part of the classroom decoration and will facilitate the teacher to foster a multicultural environment in the classroom.

\section{Thematic Strand: Literature/Arts}

With regard to the third thematic strand "Literature/Arts", the students are anticipated to raise their intercultural/multicultural awareness and their intercultural cooperation and interaction within a context that promotes mutual understanding. More specifically, the students should be able to express themselves about special and well-known people from the fields of art and literature from their own countries and all over the world. Moreover, they are expected to acquire an awareness of literary and art works and events all over the world in parallel with the development of a different sense of aesthetics.

Within a multimodal context, it is aimed to familiarize students with certain stimuli for participating in creative activities. In particular, the students may listen to/read and comprehend biographies of famous people from the fields of art and literature such as "Socrates", "Euripides" and more modern poets like "Kavafis", "Palamas" who have long been regarded as some of the most well-known people from the context of arts. Furthermore, the students will get in touch 
with literary and art works and events all over the world. They may deal with multimodal material like photos, pictures and videos that will facilitate the exchange of ideas about pieces of art work. Within the same context, they may be encouraged to show their preference to a piece of art work expressing their arguments, while they are motivated to design an art work in groups using various materials and communicating in the target language. Hence, the students will be provided with multiple opportunities of collaboration and interaction with their classmates, which is among the main goals of this particular thematic strand.

\section{Thematic Strand: Cinema/Theater}

Concerning the fourth thematic strand "Cinema/Theater", the students are aimed to raise also their intercultural/multicultural awareness in parallel with intercultural cooperation and communication. In particular, the students should be able to express themselves about famous people from the fields of cinema/theatre from their own countries and all over the world. They are also expected to acquire some knowledge of films and events all over the world and develop a different sense of aesthetics. Moreover, the students have the opportunity to come in touch with various famous personalities from Greece, the countries of the immigrant/refugee students and all over the world. They will be dealing with biographies of famous actors/actresses of Greece such as "Aliki Vougiouklaki”, "Jenie Karezi”, "Kostas Kostantaras”, “Thanasis Veggos” and others while the immigrant/refugee students will be asked to bring some information about actors/actresses from their own countries. At a second phase, all the students can be asked to bring photos and provide information about actors/actresses from all over the world. Also, the students may attend theatrical performances, live or recorded, in an attempt to see actors performing live on stage up close to them.

Furthermore, the students read reviews of cinema/theater critics, they analyze these texts, and they may be encouraged to write their own reviews. They also participate in role-play games or pantomime and explain their own judgments with specific details and points to persuade their classmates about their perspectives. Last, they can also take over the perspective of characters depicted, and they express themselves in relation to the difficulties, the feelings or the reactions of the hero through participating in role playing.

\section{Thematic Strand: Lifestyle/Customs, Habits}

In relation to the fifth thematic strand "Lifestyle/Customs and Habits", the students are expected on the one hand to empower their intercultural cooperation and communication, while on the other to enhance their language and intercultural communication strategies. More specifically, the students should be able to compare lifestyles and habits in their own and "other" cultures. They will also be able to speak and write about family relations and behaviours in various social/cultural situations focusing on comparing foods from different cultures and cuisines. It is important that students deal with visual material in relation to public places of daily life such as neighborhood, school, super marker, restaurants, bakery, etc. Within this context, the students may be engaged in role-play games in which they will simulate real-life situations of behaviours 
in public places, e.g. greeting at school, asking for help, shopping at a mall/store, asking for a loaf of bread, or looking for a product at a supermarket, etc.

In addition, the students are made to explore traditional or national dishes from the host- and 'mother' country. In particular, the students will discuss pictures of dishes while they will have the opportunity to watch videos with traditional dishes and the ways they are prepared. In this way, the students will be provided with multiple opportunities of playing roles and simulating potential visits to restaurants "ordering" and "tasting" dishes from different countries. Meanwhile, they may practice behaviours at the tables of a restaurant by ordering some food or asking for clarifications. They may also prepare their national dishes in groups, discuss the ingredients of the dishes and talk about the way these dishes are representative ones of their countries.

Another important part related to this thematic strand is the students' contact with the traditional dances/festivals as well as customs and traditions in the country of indigenous and the immigrant/refugee students. All the students can bring photos/pictures depicting traditional costumes from folk-festivals and celebrations. They may look for similarities and differentiations, they can also discuss the importance of the festivals the reason they take place in their countries. They can also create their own costumes, learn to dance traditional dance, and sing some traditional songs of their countries.

\section{Thematic Strand: Communication/Interactions}

With regard to the sixth thematic strand, students are aimed to develop their intercultural cooperation and communication skills, as well to raise their intercultural communication strategies. More specifically, the students are anticipated to be able to communicate with people coming from other countries achieving mutual understanding. They are also expected to use appropriate linguistic devices to enhance the communication and interaction with 'foreigners', while they are able to serve as effective mediators within intercultural communicative events and situations. In such an education context, the students are provided with multiple opportunities for expressing their views and perspectives as regards to their first-hand experiences. The students are engaged in interclass discussions by expressing their views about and their experiences of what it is like to be different. They may focus on expressing their feelings about how they faced situations that made them feel embarrassed.

\section{Assessing Intercultural Competence in the "Muldilanguaging" Setting}

In order to estimate the intercultural skills acquired in the "Muldilanguaging" setting, the Intercultural Portfolio could be used as an alternative tool for assessing not only the students' linguistic skills and strategies but mainly their intercultural communication skills. It may also be used as a means for motivating students, both indigenous and immigrant/minority ones, to think about cultural diversity and reflect on their multicultural experiences (Griva \& Kofou, 2019).

In other words, intercultural portfolio could be a tool for (a) emphasizing the role of multilingualism/multiculturalism; (b) motivating students to ask themselves about what they 
would like to learn in a language or culture; (c) helping students enhance their intercultural awareness and intercultural communication skills.

According to a number of researchers (see Byon, 2007; Griva \& Kofou, 2019; Lee 1997 in $\mathrm{Su}$, Ya-Chen 2011) inter/cultural portfolio could be used as an effective educational tool for integrating cultural learning with interpersonal/intercultural processes and assessing what and how students learn about the target language and the target culture. Byram (1997) also advocated portfolio assessments for estimating the dimensions of attitude, skills of interaction/discovery and relating/interpreting, and critical awareness. (Griva \& Kofou, 2019; in press).The portfolio should motivate students to think about and be aware of cultural difference, and reflect on their multi/intercultural experiences. It also contributes to promoting intercultural dialogue and encourages students to reflect on their experience with students from different countries or from diverse cultural background (see Griva \& Kofou, 2019).

For the purposes of the present study we could design an intercultural portfolio to assess students' linguistic competence, intercultural skills and intercultural communication skills. It could also be a folder that presents evidence of mastering intercultural skills, covering all the components of intercultural competence (knowledge, skills, views, qualities, cultural awareness, metacognitive strategies) (Mažeikien \& Virgailait-Meckauskait 2007, p. 81). The students are provided with the opportunity both to report on intercultural experiences and to reflect on their experience working in multicultural groups.

\section{Concluding Remarks}

In this paper, we presented a "Muldilanguaging" educational settingaiming at developing primary school students' intercultural competence (Griva \& Kofou, 2019). A “Muldilanguaging" educational setting is presented that provides students with the opportunity to understand and respect schoolmates from culturally different, accept students who belong to different cultural backgrounds, have different identities and beliefs, and be able to interact and communicate effectively and appropriately with such students (Barrett, 2013, 2018; Songul \& Akbarov, 2016). A number of communicative and creative activities are proposed with the purpose to create a group-working, cooperative context and enhance students' intercultural communicative skills in parallel with their target language skills (EFL). A number of researchers point out the need for promoting the development of cooperation and communication within culturally-diverse classrooms (see Kreijns, 2004). It is suggested that a project, based on "Muldilanguaging" educational setting, should be launched on a pilot scale that could possibly contribute to developing children's intercultural skills, sensitizing them even deeper on diversity issues, and enhancing their ability to easily distinguish differences between cultures. The implementation is proposed to be carried out in a task-based Framework (Willis, 1996), where students have the opportunity to get engaged in problem-solving 'multicultural' activities and to find solutions through co-operating, interacting and communicating in the target language. 


\section{References}

Anderson, P. H., Lawton, L., Rexeisen, R. J., \& Hubbard, A. C. (2006). Short-term study abroad and intercultural sensitivity: A pilot study. International Journal of Intercultural Relations, 30(4), 457-469.

Baker, T.,\&Clark, J. (2010) Cooperative learning: A double edged sword: A Cooperative learning model for use with diverse student groups. Intercultural Education, 21, 3, 257-268.

Barrett, M. (2018). How schools can promote the intercultural competence of young people. European Psychologist, 23(1), 93-104.

Barrett, M. (2013). Interculturalism and multiculturalism: Concepts and controversies. In M. Barrett (Ed.), Interculturalism and Multiculturalism: Similarities and Differences (pp.15-41). Strasbourg: Council of Europe Publishing.

Bennett, M. J. (1993). Towards ethnorelativism: A developmental model of intercultural sensitivity. Aus: Paige, $R M, 21-71$.

Bennett, Milton J. (1993) Towards a developmental model of intercultural sensitivity In R. Michael Paige, ed. Education for the Intercultural Experience. Yarmouth, ME: Intercultural Press.

Bennett, M. J. (2010). A short conceptual history of intercultural learning in study abroad. In W. Hoffa \& S. Depaul (Eds), A history of U.S. study abroad: 1965 to present (pp. 419-449). Carlisle, PA: Forum on Education Abroad.

Bennett, M. J. (2004). Becoming interculturally competent. Toward Multiculturalism: A Reader in Multicultural Education, 2, 62-77.

Bhawuk, D. P. S. \& Brislin, R. (1992). The measurement of intercultural sensitivity using the concepts of individualism and collectivism.International Journal of Intercultural Relations, 16, 413-36.

Byon, A. (2007). The Use of Culture Portfolio Project in a Korean Culture Classroom: Evaluating Stereotypes and Enhancing Cross-Cultural Awareness. Language, Culture and Curriculum 20 (1), 1-19.

Byram, M. (1997). Teaching and Assessing Intercultural Communicative Competence. Clevedon: Multilingual Matters

Campbell, P. S., Drummond J., Dunbar-Hall, P., Howard, K. Schippers, H., \& Wiggins, T. (2005). Cultural diversity in music education: Directions and challenges for the 21 st century. Bowen Hills, Queensland: Australian Academic Press

Chen, G. M., \& Starosta, W. J. (1996). Intercultural communication competence: a synthesis. Communication Yearbook, 19, 353-383.

Chen, G.M., \& Starosta, W. J. (2000). The development and validation of the intercultural communication sensitivity scale. Human Communication, 3, 1-15.

Chen, Guo-Ming. (2014). Intercultural Communication Competence: Summary of 30-year Research and Directions for Future Study. In Dai, Xiadong \& Guo-Ming(Eds), Intercultural Communication Competence Conceptualization and its Development in Cultural Contexts and Interactions (pp. 14-40). Newcastle: Cambridge Scholars Publishing.

Coelho, E. (1998). Teaching and learning in multicultural schools. An integrated approach. Clevedon: Multilingual Matters Ltd.

Crandall, J., Jaramillo, A., Olsen, L., \& Peyton, J.K. (2001). Diverse teaching strategies for immigrant children. In R. W. Cole (Ed.), More strategies for educating everybody's children. Alexandria, VA: Association for Supervision and Curriculum Development.

Griva, E. \& Papadopoulos, I. (2019).Teachers Sketch the Student Profile in a Multicultural/Multilingual Classroom. In R. Nata (Ed), Progress in Education (59), pp. 79-102. NY: Nova Press Publ.

Griva, E.,\& Kofou, I. (2019). Language portfolio serving as a tool for developing/assessing multilingual skills and inter/multicultural competence. In N. Bakic, M. Loncar \& M. Jakovljević(Eds), Current Topics in Language and Literature - An International Perspective (pp. 67-93). Cambridge Scholars Publishing. 
Griva, E., \& Kofou, I. (2019 in press). The Intercultural Portfolio as a tool for developing/assessing learners' multilingual/ multicultural skills and strategies. Proceedings of the fourth International conference Educational Across Boarders, University of Western Macedonia.

Griva, E. \& Zorbas, V. (2017). Multicultural and citizenship awareness through language: cross thematic practices in language pedagogy. New York: Nova Science Press.

Griva, E., \& Stamou, A. (2014). Researching Bilingualism in the Context of Greek Schooling: Teachers', Students’ and immigrant Parents' views. (In Greek). Thessaloniki: D. Kyriakidis Editions.

Hammer, M. R., Bennett, M. J., \& Wiseman, R. (2003). Measuring intercultural sensitivity: The intercultural development inventory. International Journal of Intercultural Relations, 27(4), 421-443.

Johnson, D. W., \& Johnson, R. (1989). Cooperation and competition: Theory and research . Edina, MN: Interaction Book Company.

Johnson, F. L. (2003). Cultural Dimensions of Discourse. In L. A. Samovar, \& R. E. Porter (Eds.), Intercultural Communication (pp. 187-198) . Belmont, CA, USA: Wadsworth/Thomson Learning.

Kramsch, C. (1993). Context and culture in language teaching. Oxford: Oxford University Press.

Kreijns, K. (2004). Sociable cscl environments: Social affordance sociability and social presence. Educational Technology Expertice Center (OTEC). Maastricht: Open University.

Lambert, M. J., \& Barley, D. E. (2001). Research summary on the therapeutic relationship and psychotherapy outcome. Psychotherapy, 38(4), 357-361.

Landis, D., \& Bhagat, R. (1996). Handbook of Intercultural Training. Sage Publ.

Mažeikien, N. \& Virgailait_-Meckauskait, E. (2007). The Experience of Measurement and Assessment of Intercultural Competence in Education. Social sciences / Socialiniai Mokslai,58 (4),70-82.

Saravia-Shore, M., \& Garcia, E. (1995). Diverse teaching strategies for diverse learners. In R. W. Cole (Ed.), Educating everybody's children: Diverse strategies for diverse learners (pp. 47-74). Alexandria, VA: Association for Supervision and Curriculum Development.

Seidel, G. (1981). Cross-cultural training procedures: Their theoretical framework and evaluation. In S. Bochner (Ed.), The mediating person: Bridge between cultures. Cambridge: Schenhman.

Snowman, J., \& Biehler, R. (2003). Psychology applied to teaching. Boston: Houghton Mifflin.

Songul, D., \& Akbarov, A.(2016). How Teachers Facilitate Intercultural Communicative Competence in Multicultural Settings. Education, 6, 48-57.

$\mathrm{Su}$, Ya-Chen. (2011). Promoting intercultural understanding and reducing stereotypes: incorporating the cultural portfolio project into Taiwan's EFL college classes. Educational Studies,37(1), 73-88.

Tielman, K. A., Brok, den, P. J., Bolhuis, S. M., \& Vallejo, B. (2012). Collaborative learning in multicultural classrooms : a case study of Dutch senior secondary vocational education. Journal of Vocational Education and Training, 64(1), 103-118.

Thomas, K., \& Althen, G. (1989). Counseling foreign students. In P. B. Pedersen, J. G.Draguns, W. J. Lonner, \& J. E. Trimble (Eds.), Counseling across cultures ( pp. 205-241). Honolulu, HI: University of Hawaii Press.

Triandis, H. C. (1977). Theoretical framework for evaluation of cross-cultural training effectiveness. International Journal of Intercultural Relations, 1, 195-213.

Ward, C., Wilson, J., \& Fischer, R. (2011). 'Assessing the predictive validity of cultural intelligence over time', Personality and Individual Differences, 51, 138-142.

Willis, J. (1996). A framework for task-based learning. London: Longman.

Yassine, S. (2006). Culture Issues in FL teaching: Towards the fostering of intercultural awareness.Annales du Patrimoine, 5, 51-61. 